\title{
Functional Finishing of eri silk and its union fabrics for hydrophobicity
}

\author{
Mamoni Probha Borah ${ }^{1}$ | Binita Baishya Kalita ${ }^{2}$
}

${ }^{1}$ Dept of Textile and Apparel Designing, College of Community Science, Central Agricultural University, Tura, Meghalaya, India, 794005, Email:mamoni.p.borah@gmail.com

${ }^{2}$ Dept of Textile and Apparel Designing, College of Community Science, Assam Agricultural University, Jorhat, Assam, India, 785013, Email:Baishyakalitab@rediiffmail.com

\section{To Cite this Article}

Mamoni Probha Borah and Binita Baishya Kalita, "Functional Finishing of eri silk and its union fabrics for hydrophobicity", International Journal for Modern Trends in Science and Technology, 6(9S): 175-182, 2020.

\section{Article Info}

Received on 25-August-2020, Revised on 08-September-2020, Accepted on 12-September-2020, Published on 18-September-2020.

\section{ABSTRACT}

A novel approach was attempted for the functionalization of eri and its union fabrics with polymers for water repellency finishes. For the study, eri fabric was prepared with plain weave structure using $1 / 140$ s and 2/140s (warp and weft directions) and 2/140s of eri and 1/56s of wool yarn for the union fabric in both the warp and weft directions. For surface enrichment, silicone polymer was applied by the pad-dry-cure method. The untreated and treated fabric was evaluated for its hydrophobicity like the water contact angle and spray test, air permeability and physio-mechanical properties viz., counts, GSM, thickness, bending length, crease recovery, tensile strength and elongation were assessed. Analytical tests like UPF, whiteness, brightness, yellowness index for surface appearance was evaluated and SEM was performed. The marginal enhancement in bending length was observed in treated eri silk and union fabrics in both directions. The properties like thickness, brightness, yellowness, increased after application of silicone polymers, while crease recovery decreased. Noticeable enhancement of water contact angle was observed in eri silk and union fabric after adding silicone polymer and UPF was found to be excellent. There was no structural damage observed in all treated samples which are cleared from the Scanning Electron Microscope view. Application of silicone polymer on eri silk and its union fabrics improved the hydrophobic characteristic. The UPF protection properties were evaluated on both fabrics and recorded excellent UPF. In this study, the functional properties on eri silk and union fabrics were achieved successfully for functional clothing and textiles.

KEY WORDS: Eri silk, union fabric, polymer, hydrophobicity, functional finish.

\section{INTRODUCTION}

The use of natural fibers has gained a lot of attention in numerous fields due to their several superior properties that have the potential of replacing the use of synthetic fibers. Natural fibers are environmental friendly, sustainable, low cost, have high specific properties, nonabrasive, high strength, $\mathrm{CO}_{2}$ sequestration, and posses high availability [1]. The survival of textile industries depends primarily on the diversification of current end products to meet national as well as international demands. 
Now a day's Clothing has many more functions like a status symbol, beautifying agent, the fitness guide, multitasking device and personality developer in an era of smart clothing. In order to enhance the functional features, clothing today is expected to be waterproof, fire retardant, self-cleaning, protection from UV light, warmer in winter and cooler in summer while at the same time lightweight and less bulky [2]. Textile material containing more than one type of textile fibers is termed as blend, union or mixture. The reason for developing such union fabrics is to economize on raw material cost, to modify and confer aesthetic properties or to develop a material with specific physical characteristics [3]. Union fabrics can be developed with two different kinds of yarns in the warp and weft direction as well as using different blended yarn in both warp and weft direction of fabric that creates novelty effect to cater the today's fashion world $[4,5]$.

Silk is the most cherished and known as the queen of all the fibers and has the most exciting characters like extra luster, extremely smooth feeling and good insulation. Eri fiber possesses a unique dual nature with excellent strength and softness properties [6]. Eri Silk is known asPhilosamiarecini, fibers have tremendous blending/ union possibilities with other fibers like cotton, lyocell, rayon, and compatible to interweave with wool. Eri silk cocoons are open-mouthed, off white in colour with strong typical texture. The staple length of the fiber is about $57 \mathrm{~mm}$. It has excellent thermal properties, which can be a substitute for wool [7]. Wool is a unique animal protein, fiber enjoys a special position among textile fibers because of its unmatched properties of warmth, excellent drape, high absorbency, outstanding stretchability, excellent resilience, water repellent, flame retardancy, crispness and superior compression recovery [8].

Union of silk and wool is a way to incorporate better appearance, serviceability and strength in the woolen fabric and increase the utility of silk fabric [9]. Diversified textile products can be produced by the combination of silk with other textile fibers to reduce the cost of the silk fabric and enhance the luster, good hand property, strength and colour brilliance [10, 11, 12, and 13]. Finishing is used to improve the attractiveness and/or serviceability of the textile material, mostly in fabric form. There are many finishing processes, each producing a different effect. Silicone is the most versatile organo-metallic polymers derived from the abundant raw material on earth, sand and has wide application in the textile processing and finishing. The primary applications of silicone in the textile are fabric softening agents and lubricants [14].

The performance of silicone polymer varies depending upon the functionality and molecular weight. It offers a wide range of functional properties like durable softness, sew ability, lubricity, elasticity, hydrophobicity, hydrophilicity, wrinkle and stretch recovery [15]. Silicone's side chains which most commonly consist of methyl groups render the polymer hydrophobic, making it useful for applications that may require repelling water [16, 14]. Eri fibers, yarns, and fabrics are the most unexplored, underutilized sector in the textile industry. Limited amount of researches was observed on hydrophobicity on eri silk and its union fabrics through the application of polymer. Therefore, union fabrics were prepared by interweaving eri silk with wool yarns and silicone polymer was added for functional finishes to add the value of union fabrics. The different mechanical and analytical properties were investigated, so that every consumer can enjoy the unique richness of eri silk with excellent softness and quality wool's wrinkle resistance, crease retention, flexibility, elasticity, absorbency and warmth in cold climates along with water repellency.

\section{MATERIAL AND METHODS}

In this experiment, the union fabric was prepared by using natural eri silk yarns in warp and wool yarns in weft way having 130 GSM. Apart from the union fabric, the Eri silk fabric with 85 GSM was also woven in fly shuttle loom. For functional finishing silicone polymer was sourced from Resil Company Private Limited and citric acid was used.

\section{Scouring of fabric}

The samples were scoured by using $1 \%$ non ionic detergent (Ultravon JU). The material to liquor ratio was kept at 1:20 for scouring of fabric. The temperatures of the scouring baths were gradually raised to $80^{\circ} \mathrm{C}$ and continued for 30 minutes. After scouring, the eri fabric were squeezed out to remove the excess water and dried at an ambient temperature.

\section{Application of silicone polymer}

A solutions $1 \%$ silicone polymer $(\mathrm{W} / \mathrm{V})$ were prepared with water and citric acid $(0.01 \mathrm{~V} / \mathrm{V} \%)$ 
was added. The prepared solution was applied on eri silk and eri-wool union fabric by following high temperature (Exhaust) method in which $50.0 \mathrm{~g}$ of each sample was kept in a steel beakers containing $1 \%-2 \%$ silicone polymer solution with liquor ratio 1:15. The beakers were heated in Infrared heating chamber up to $90^{\circ} \mathrm{C}$ for 30 min with constant rotational stirring. After that beakers were cooled and the fabric samples were passed though a padding mangle with $100 \%$ weight expression. The treated sample were dried in an oven for 5 minutes at $80^{\circ} \mathrm{C}$ and cured at $150^{\circ} \mathrm{C}$ for 2 minutes.

\section{Conditioning of samples}

Prior to testing, all the samples were conditioned to attain moisture equilibrium and tested in standard atmospheric condition of $65 \pm 2 \%$ relative humidity and temperature $27 \pm 2{ }^{\circ} \mathrm{C}$ as per IS standard Method IS-6359-1971.

\section{Assessment of Physio-mechanical properties}

The fabric count and GSM of the untreated eri silk fabric, union fabrics and treated fabric were determined by using standard methods. The fabric thicknesses of the samples were analyzed according to BS test method 2544:1954. The bending lengths of all the samples were tested using a stiffness tester at $45^{\circ}$ angle by following ASTM- D-1388 method. Crease recovery (degree) was also tested according to I.S method: 4681-1968 by using the Shirley's crease tester [17]. The tensile strength, elongation of control eri silk fabric, union fabric as well as treated fabrics was analyzed according to ASTM D-5035 test method by using Instron tensile tester -5965 , UK.

\section{Contact angle measurement}

The contact angles and surface free energy were measured using a drop deposition method, in which a drop of liquid is placed on a solid surface. The images of the drop were taken and analyzed by computer software. Measurements of the water contact angle were performed using a Kruss DSA30E instrument from Kruss $\mathrm{GmbH}$, Germany.

\section{Spray test}

For spray test FTTS-FA-011 (Water Repellent Textiles) method was followed. The sample fabrics was mounted on the embroidery hoop and fixed on the instrument at $45^{\circ}$. The water repellency is assessed from the spray rating chart.

\section{Analysis of Whiteness, Yellowness and Brightness Index}

The whiteness, brightness and yellowness of untreated and silicone polymer treated union fabric was measured using Premiere Spectra Scan $5100+$ computer matching system at $10^{\circ}$ Observer.

\section{Analysis of Ultraviolet Protection Factor (UPF)}

The UPF values of the untreated and treated fabrics were measured using a Shimadzu UV-2600 spectrophotometer in the range of 280 to $400 \mathrm{~nm}$. The UPF value of each fabric was determined from the total spectral transmittance based on AS/NZS 4399:1996 methods.

\section{Scanning Electron Microscope (SEM)}

The surface morphology of untreated and treated union fabric was analyzed by using Scanning Electron Microscope (Nova Nano FESEM- 450, Netherland) with suitable magnification.

\section{FINDING AND DISCUSSIONS}

\section{Constructional details fabrics}

The eri silk fabric with plain weave was woven in fly shuttle loom. The eri silk yarns with $\mathrm{S}$ twist are used in warp is $2 / 140 \mathrm{NE}$ and in weft $1 / 140 \mathrm{Ne}$. While, for union fabric, $\mathrm{S}$ twist yarns are used, eri silk yarns with 2/140 Ne in the warp direction and $1 / 56 \mathrm{Ne}$ of wool yarns with $\mathrm{S}$ twist were used to obtain plain weave fabric. These plain-woven fabrics are used for the application of functional finish (table 1).

Table 1. Constructional details of Eri silk and Union

\begin{tabular}{cccccc}
\multicolumn{5}{c}{ Fabrics } \\
\hline Fabric & Yarn & $\begin{array}{c}\text { Twist } \\
\text { direction }\end{array}$ & $\begin{array}{c}\text { Yarn } \\
\text { count }\end{array}$ & $\begin{array}{c}\text { Yarn } \\
\text { type }\end{array}$ & Direction \\
\hline $\begin{array}{c}\text { Eri silk } \\
(\mathrm{EE})\end{array}$ & $\begin{array}{c}\text { Eri } \\
(100 \%) \\
\text { Eri }\end{array}$ & S twist & $2 / 140$ & 2 ply & Warp \\
& S Twist & $1 / 140$ & 1 ply & Weft \\
$\begin{array}{c}(100 \%) \\
\text { Eri/wo } \\
\text { El }\end{array}$ & $\begin{array}{c}\text { Eri } \\
100 \%\end{array}$ & S twist & $2 / 140$ & 2 ply & Warp \\
union & Wool & S twist & $1 / 56$ & 1 ply & Weft \\
$($ EWU $)$ & $(100 \%)$ & & & & \\
\hline
\end{tabular}

Fabric thickness and fabric count

Table 2, inferred that the thickness of silicone polymer treated fabrics showed an increasing trend as compared to untreated eri silk and its union fabrics. The highest thickness 33.75 and $39.25 \mathrm{~mm}$ was observed in eri silk as well as union fabric treated with $2 \%$ silicone polymer. But as compare to control eri fabrics there was a slight difference in thickness value that was found in treated fabrics. This is because, these coatings are more 
homogenous which helps in yarn binding and also higher percent of silicone polymer make the fabrics surface somewhat thick and rough [18]. The difference in thickness may be also due to the fibers types, yarn twist and fabric structure [19]. In general, it was noticed that the untreated eri silk has (74) EPI and (69) PPI that is higher than (1\% and2 \%) silicone polymer treated eri silk fabric. Moreover, a similar trend was also reflected by polymer treated union fabric (EPI 70 and PPI 73). The values of warp direction are lower than the weft direction in union fabric and vice versa in eri silk fabric.

\begin{tabular}{|c|c|c|c|c|c|c|c|}
\hline \multirow[t]{2}{*}{ Sample } & \multirow{2}{*}{$\begin{array}{c}\text { Fabric } \\
\text { thickness } \\
\text { (mm) }\end{array}$} & \multicolumn{2}{|c|}{$\begin{array}{l}\text { Fabric } \\
\text { Count }\end{array}$} & \multicolumn{2}{|c|}{$\begin{array}{c}\text { Bending } \\
\text { length }(\mathrm{cm})\end{array}$} & \multicolumn{2}{|c|}{\begin{tabular}{|c|} 
Crease \\
Recovery $\left({ }^{\circ}\right)$
\end{tabular}} \\
\hline & & EPI & PPI & Warp & Weft & Warp & Weft \\
\hline EE(control & 33.00 & 74 & 69 & 2.22 & 2.25 & 94 & 96 \\
\hline $\begin{array}{l}\text { EEP } \\
(1 \% \\
\text { polymer })\end{array}$ & 33.25 & 72 & 68 & 2.35 & 2.28 & 90 & 86 \\
\hline $\begin{array}{l}\text { EEP } \\
(2 \quad \% \\
\text { polymer })\end{array}$ & 33.75 & 70 & 67 & 2.50 & 2.34 & 87 & 83 \\
\hline $\begin{array}{l}\text { EWU } \\
\text { (control) }\end{array}$ & 36.80 & 78 & 79 & 2.16 & 2.47 & 91 & 89 \\
\hline $\begin{array}{l}\text { EWUP } \quad(1 \\
\% \text { polymer })\end{array}$ & 38.80 & 73 & 75 & 2.63 & 2.93 & 90 & 83 \\
\hline $\begin{array}{l}\text { EWUP } \quad(2 \\
\% \text { polymer })\end{array}$ & 39.25 & 70 & 73 & 2.85 & 3.15 & 87 & 79 \\
\hline
\end{tabular}

The data in the table represent the average of five tests; Note: $E E$ $=100 \%$ eri silk fabric; EEP $=100 \%$ Eri Silk fabric treated with silicone polymer; $E W U=E r i / W o o l$ Union fabric and $E W U P=E r i$ $/$ Wool Union fabric treated with silicone polymer, EPI = ends per inch and $P P I=$ picks per inch).

Hence, it can be opined that after the application of silicone polymer the EPI and PPI decreased, it may be due adherence of silicone polymer in between the weave of yarn as result the warp yarn and weft yarn move away from each other. The fabric construction like (count and weave type) proves to be playing a major role in the performance of the fabric [20].Fabric aesthetics properties are associated with thickness, count, crease and surface properties.

\section{Bending length}

A bending test measures the severity of the flexing action of any textile material. The stiffness of a fabric in bending length is very dependent on its thickness [22].The bending length of untreated eri silk and eri union fabric exhibited a decreasing trend. As seen from the table chemical coating make fabrics stiff due to their rigidity. Bending length of treated eri and its union fabrics increased gradually with silicone polymer concentration (2.22-2.50 cm warp and $2.25-2.34 \mathrm{~cm}$ weft) directions. It was observed that higher the stiffness of the fabrics then higher the bending length was noticed [22]. This may be due to the absorption of silicone polymer by the fiber molecules. The marginal enhancement in bending length was observed in treated eri silk fabrics and union fabrics in both warp and weft direction.

\section{Crease recovery}

The crease recoveries of control and treated eri silk and union fabrics were assessed. It was noticed from table 2 that the crease recovery of untreated eri silk was found as $94^{\circ}$ in warp and $96^{\circ}$ in weft directions. The silicone polymer treated eri silk fabric showed a noticeable change in crease recovery $90^{\circ}$ to $87^{\circ}$ in warp and $86^{\circ}$ to $83^{\circ}$ in weft directions. While gradual changes in crease recovery angle were observed in untreated and treated union fabrics that maybe the increase of concentration of silicone polymer contribute stiffness as a result the crease recovery angle decreased. It also appears that applications of silicone polymer on eri silk and union fabric have a direct effect on the bending rigidity of the fabrics. The stiffness is also related to the softness and hardness of the fabrics $[23,22]$.

\section{Analysis of Water repellency}

Data in table 3, inferred that, the contact angle of silicone polymer treated eri silk fabric was higher than untreated fabric. The water contact angel of untreated eri silk fabric was found to be $77.6^{\circ}$. The eri silk fabric treated with $1 \%$ silicone polymer showed a contact angle of $119.6^{\circ}$, which was increased up to $136.2^{\circ}$ by the enhancement of concentration up to $2 \%$ silicone polymer $(75.5 \%$ enhancement). A positive trend in water contact angle was observed along with silicone polymer concentration on eri silk fabric. All the treatments registered a contact angle $>90^{\circ}$, which indicates that, the fabric is hydrophobic in nature. Similarly an increasing trend in water contact angle with the increase in concentration of silicone polymer was observed in eri/wool union fabric. the hydrophobic character (fig.1.a, b, c and d).

Table 3. Water Contact angle, Spray test and Surface properties of eri silk and union fabrics. 


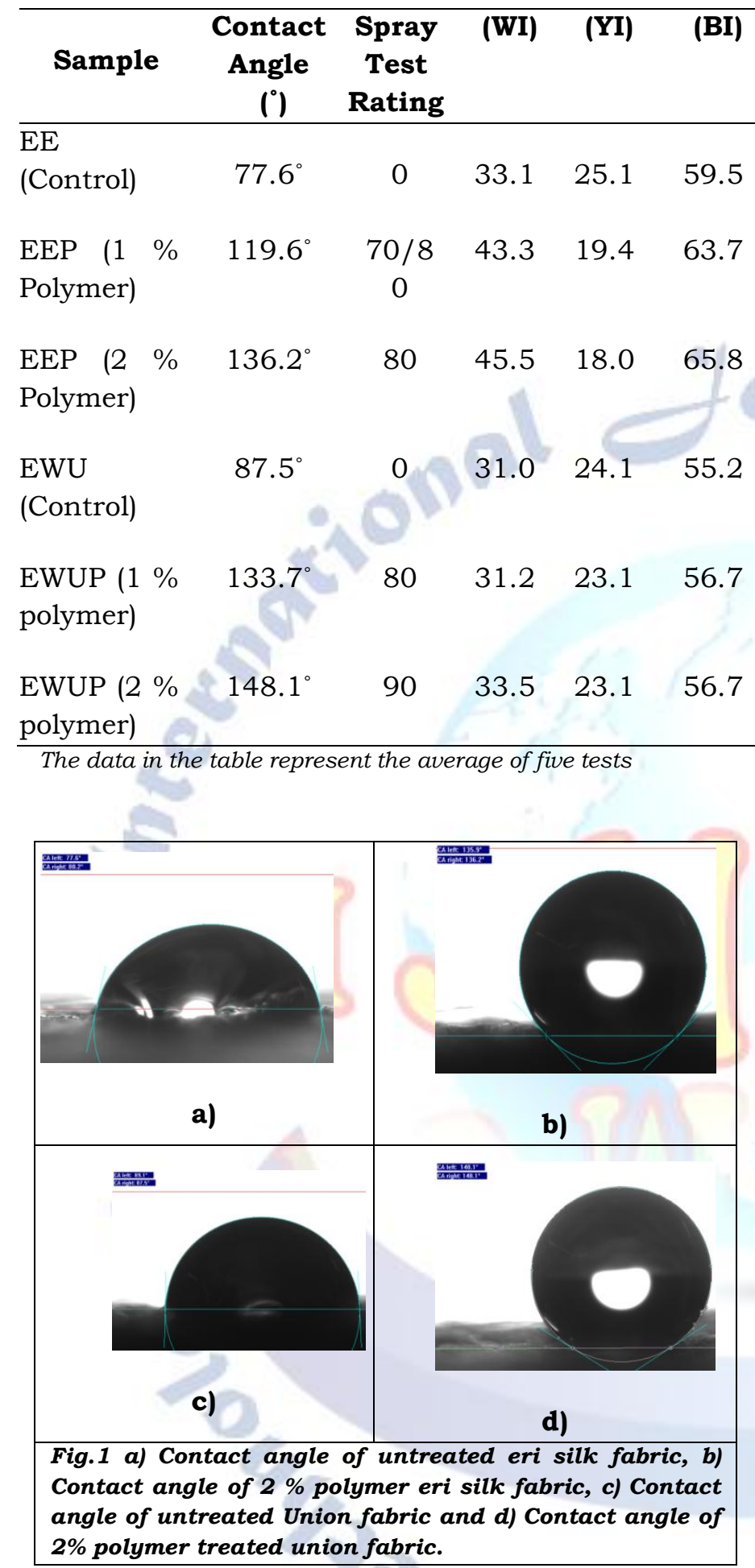

The water contact angle of $1 \%$ polymer treated union fabric was found to be $133.7^{\circ}$, which was increased up to $148.1^{\circ}$ by the enhancement of concentration up to $2 \%$. It was also observed that, there is $69 \%$ enhancement in water contact angle of union fabric after adding silicone polymer. This is certainty due to that nano-particles have a larger surface area per unit mass and volume leading to the increase the effectiveness of fabric water repellency. When the polymer is added, it enhanced the hydrophobic character of eri silk fabric due to synergic effect of polymer treatment [24]. Hence, it can be opined that, the silicone polymer can be successfully applied to eri and its union for improvingthe hydrophobic character (fig.1.a, b, c and $\mathrm{d})$.

\section{Spray test}

It was observed that, there is an increasing trend in water repellant in spray test rating scale from 70 (partial wetting of whole upper surface) to 80 rating that enhanced up to $80 \%$ (wetting of upper surface at spray points- good)with the increase of concentrations up to $2 \%$ silicone polymer. With the increase in percentage of silicone polymer the hydrophobicity of treated eri silk fabric increased. Therefore, the application of silicone polymer played an important role and showed positive trend in the enhancement of hydrophobicity of eri silk fabric. The untreated eri silk and union fabrics were found to be complete wetting of the whole upper and lower surface which ensured that both fabrics were hydrophilic in nature. Regarding union fabric, after application of $1 \%$ silicone polymer, it showed 80 rating as in the scale (slight random sticking or wetting of upper surface) and 2 $\%$ silicone polymer showed 90 rating (slight random sticking or wetting of upper surface -very good). In treated union fabric an encouraging hydrophobicity properties was also observed may be due to the penetrating of silicone polymer in surface of fabric.

\section{Analysis of Surface appearance}

The surface appearance of eri silk and its union (eri/wool) fabric was studied and results were presented in table 3 . The whiteness index increased from 33.10 to 45.5 in eri silk fabric after treated with silicone polymer and similar trend was observed in union fabric (31.01 to 33.50). Regarding yellowness index decreasing trend was observed in the eri silk and union fabrics. In case of brightness index increasing trend was observed after application of polymer in eri silk and its union fabric compared to untreated fabrics. This may be due application of silicone polymer that may create a coating on the fabrics which enhanced the surface properties.

\section{Ultra violet protection factor (UPF)}

The protection extended by the textile materials with different finishing agents and methods are denoted by different terminologies known as UPF (Ultra Violet Protection Factor) and SPF [26, 26]. The construction parameters and wear conditions 
of the textile materials, moisture and additives incorporated in processing also affect the UPF of the textile materials $[27,28,29]$. The ultraviolet protection factor of untreated and treated eri silk as well as union fabric were illustrate in table 4. It was confirmed from the results that eri silk both untreated and treated have less UPF values of 8.40, 11.01 , and 13.89 respectively. While both the untreated and treated union fabric showed 15.99, 35.94 and $37.80 \mathrm{UPF}$ value at $290-400 \mathrm{~nm}$ of wavelength. The silicone polymer in fact enhances the UV blocking properly due to their increase surface area and intense absorption in UV region [30]. It may also be because of more fabric density and thickness as well as less the porosity [31]. Therefore, the fabrics give high UPFs with the maximum number of yarns in warp and weft. Moreover, presence of wool fibers also helped to enhance the UPF property of the union fabric. Thus, the application of nano silica with higher \% could successfully improve the UPF property of eri silk and its union fabrics. The larger surface area of the nanoparticles makes it possible to increase the effectiveness of UV blocking property [32, 33].

\begin{tabular}{|c|c|c|c|c|}
\hline Fabrics & $\begin{array}{c}\text { UVA } \\
\text { (315 - } \\
400 \mathrm{~nm})\end{array}$ & $\begin{array}{c}\text { UVB } \\
\text { (290 - } \\
315 \mathrm{~nm})\end{array}$ & $\begin{array}{c}\text { UPF } \\
(290 \\
-400 \\
\mathbf{n m}) \\
\end{array}$ & Category \\
\hline
\end{tabular}

\begin{tabular}{lcccc}
\hline $\begin{array}{l}\text { EE } \\
\text { (control) }\end{array}$ & 17.73 & 9.82 & 8.46 & - \\
$\begin{array}{l}\text { EEP (1\%) } \\
\text { EEP (2\%) }\end{array}$ & 16.07 & 7.20 & 11.01 & - \\
& 15.00 & 6.25 & 13.89 & - \\
$\begin{array}{l}\text { EWU } \\
\text { (Control) }\end{array}$ & 13.21 & 4.95 & 15.99 & Good \\
$\begin{array}{l}\text { EWUP } \\
(1 \%)\end{array}$ & 8.45 & 2.02 & 35.94 & Excellent \\
$\begin{array}{l}\text { EWUP } \\
(2 \%)\end{array}$ & 8.00 & 1.85 & 37.80 & Excellent \\
\hline \multicolumn{2}{l}{ The data in the table represent the average of five tests. }
\end{tabular}

\section{Tensile and elongation properties}

The tensile strength, elongation properties of untreated and treated eri silk as well as union fabric was depicted in table 5. It was seen that the untreated eri silk fabric showed (252 N and $235 \mathrm{~N}$ ) strength both warp and weft directions while elongation was found to be $0.34 \mathrm{~mm}$ and $0.39 \mathrm{~mm}$ in warp as well as weft way. The tensile strength of treated eri silk fabric was decease from $(252 \mathrm{~N}$ to $175 \mathrm{~N}$ and $235 \mathrm{~N}$ to $172 \mathrm{~N}$ ) in both directions. This may be due to the application polymer make the surface rough and inflexible. In case of union fabric, both the treated and untreated fabrics result clearly indicates that, there was not much changes observed in tensile strength. There was adecreasing trend in tensile strength in both warp and weft direction after application of silicone polymer in eri silk and its union fabric. In case of elongation, an increasing trend was noticed in both eri silk and union fabric in weft directions. Higher elongation (\%) may be due to fiber content of eri silk, which is considered to be more plastic than elastic. The every crystalline polymer system of eri silk does not resist the polymer movement. When the silk is stretched additionally the polymers, which are already in stretched state and will not elongate further [34]. The result clearly indicates that the breathability of the fabric is not getting affected after application of polymer.

Table 5. Tensile strength $(\mathrm{N})$ and elongation of eri silk and union fabrics.

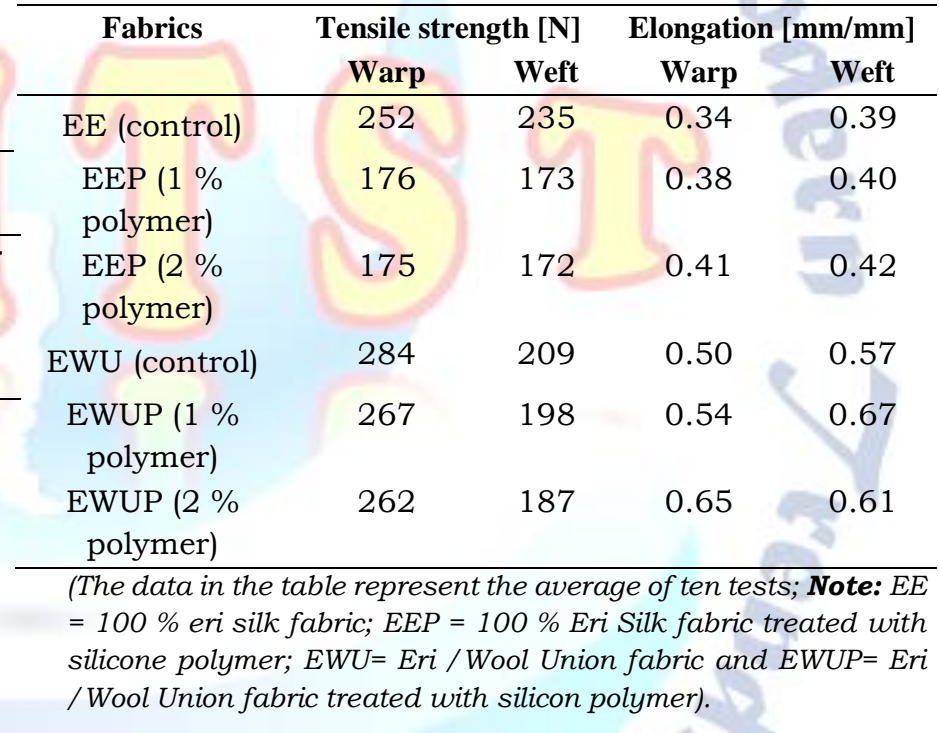

\section{Scanning Electron Microscope (SEM)}

The SEM images of all untreated and silicone polymer treated fabric were presented in Figure 2. SEM is generally used to observe surface structures of materials. Figure 2 (a) and (b) depicted the image of untreated eri silk and union fabric. The SEM image of eri silk fabric samples showed smooth round angular shape, structure while the union fabrics showed scales on the fiber and smooth round angular shaped because of fabric construction. However, no damaging effect could be seen on the silicone polymer treated fabric in both eri silk and union fabric since it was tightly woven and have fibrous structure. From figure 2(c) it was observed a typical smooth longitudinal fibril structures along with scales were appears in union fabric. There was an adhesion of silicone polymer 
particles on the fibers of eri silk and union fabrics, as shown in figure 5(c) and (d). After application of silicon polymer treatment the fiber exhibited a compact coating with polymer clusters, which made the surface a lotus effect on the union fabric. A silicone polymer coated on the eri silk and union fabrics penetrates them easily and forming a film on the surface of the fabrics which helped in obtaining hydrophobicity.

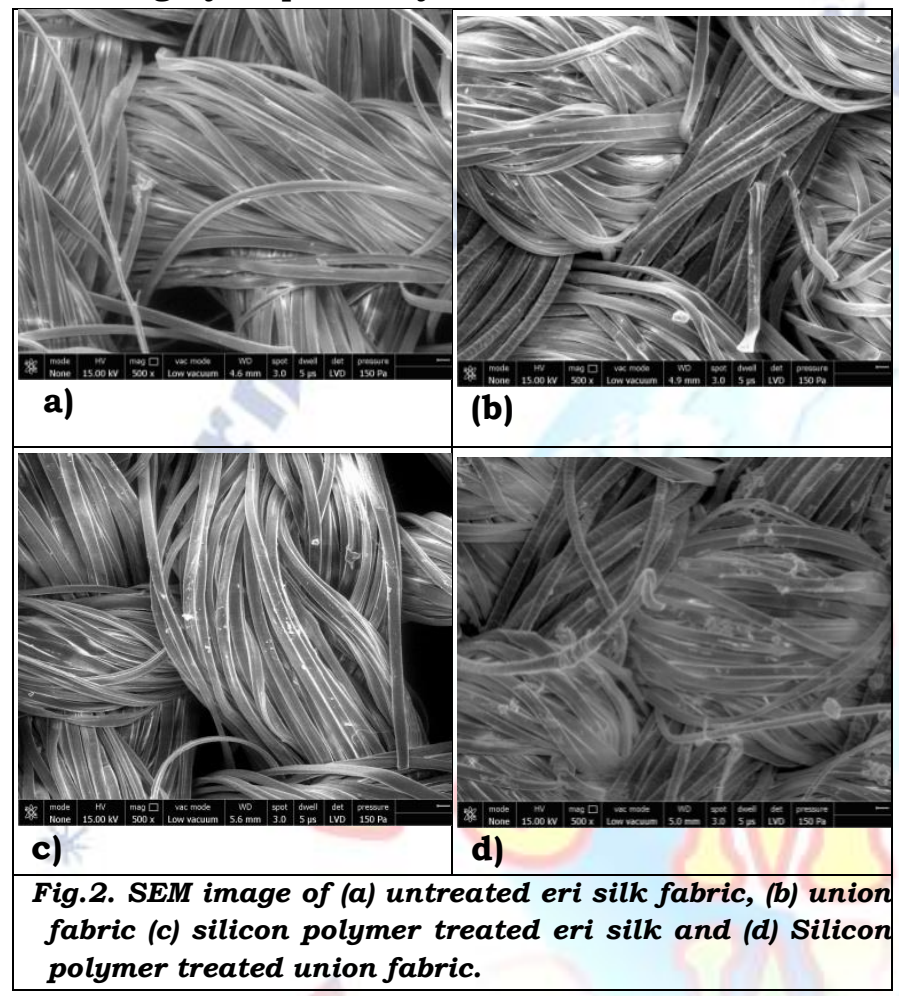

\section{CONCLUSION}

In the present study silicone polymer finishes with different concentration was applied to eri and its union fabric to impart water repellent properties. The water contact angle of eri silk and union fabric increased after application of silicone polymer which confirmed that hydrophobicity can be achieved by application of silicone polymer. The thickness of treated eri silk and union fabric increased while a marginal enhancement was noticed in bending length. Regarding crease recovery and air permeability decreasing trend were observed after application silicone polymer in both the fabrics. The tensile strength was more in warp direction then weft direction. Elongations were found more in weft direction than warp way in all the samples. However, the percent of elongation in treated fabric was more compared to untreated fabrics. The silicone polymer treated union fabrics have showed excellent UPF. Under SEM, no damage was observed in fiber structure after application of polymer. The whiteness index and brightness index of treated eri silk and union fabric increased but yellowness index decreased. Hence, it was concluded that silicone polymer leads to improvement of physio- mechanical properties of natural eri silk and its union fabric. The different functional properties like hydrophobic, UPF protection on eri silk and union fabrics can be achieved for functional clothing and textiles. The union fabric being prepared from natural fibers and are eco friendly can be exploited at the fullest for different end use in the textile industries to attract consumers with aesthetic and functional properties.

\section{ACKNOWLEDGEMENT}

We acknowledge our sincere thanks and gratitude to Assam Agricultural University, Jorhat, Assam and Dept of Textile Manufacturing and Mr Seiko Jose, Scientist, Textile Chemistry, CSWRI -ICAR Avikanagar Rajasthan for rending all supports to conduct the study.

\section{REFERENCES}

1. Yousif, B.F., Orupabo, C., \&Azwa, Z. N.(2012). Characteristics of Kenaf Fiber Immersed in Different Solutions; Journal of Natural Fibers, 9(4), 207-218

2. Gulrajani, M. L. and Gupta Deepti (2011). Emerging techniques for functional finishing of textiles, Vol. 36, pp 388-397

3. Adnan, M., \& Moses, J. J. (2013).Investigations on the effects of UV finishes using titanium dioxide on silk and lyocell union fabrics, Journal of Textile and Apparel, Technology and Management, 8(2).

4. Arora, R., and Sharma S.,(2010). Physical properties of silk based union fabric, J. Ind. Silk 49, no. 2 (: 24-25

5. Kulkarni, A. A., \&Mahale, G. (2012).Physical properties of developed viscose rayon and eri silk union fabrics, Karnataka J. Agric. Sci., 24 (4) : (506-509).

6. Boruah, S., Kalita B. B., Jose Seiko, Borah M.P, and Kalita S. (2020).Thermo-physical Comfort Properties of Eri/Acrylic Union Fabrics, Journal of Natural Fibers, pp 1-9.

7. Sreenivasa, I., Kumar, H. L. V., \&Nadiger, G. S. (2005).Development and study of the properties of eri silk and polyester blended yarn. Man Made Textiles in India. 48(1): pp15-18,

8. Verma N. (2011). Characteristics of yarns and fabrics developed by using mulberry silk waste/wool blends (Doctoral dissertation, PAU Ludhiana)

9. Borah, M. P., Kalita B. B. and Phukan A R.(2019). Physio-mechanical properties of Eri silk and its union fabrics, IJCS 7, no. 1; pp2398-2401,

10. Gill P and Singh O.P. (2002). Value addition of wool through blending, Textile Trends 44: pp27-29.

11. Shilpa, P, Verma, V. \& Gupta, M.,(2007). Growing importance of cotton blends in apparel market. J. Tex. Assoc, 67(5), pp201-210

12. Subramanian Senthilkannan Muthu (2017). Sustainable Textile Fiber, Book, Textile Institute, Woodhead Publishing, pp2-3 
13. TagaGabur and Kalita B.B. (2013). Study on Eri Union Fabric for Various End-Uses, Journal of Academia and Industrial Research (JAIR), Volume 2, Issue 5 October 2013, Youth Education and Research Trust (YERT), pp251-255

14. Islam, MdMoyinul, Islam Ashraful and Huiyu Jiang,(2015). Silicone softener synthesis and application on knit and woven white cotton fabrics, American Journal of Polymer Science \& Engineering 3, no. 1: 129-138,

15. Sundar N. (2018). Silicone finishes for textiles, https://www.fibre2fashion.com/industry-article/4998/si licone-finishes-for-textiles 2018; (2018), accessed on April 27, 2018

16. Manickam, M. Muthu (2006). Silicone chemistry for fabric care, J. Colourage 56: pp86

17. Booth J. E.(1968).Principle of Textile Testing; Newness-Butterworths.

18. Saleemi, Mohsin, Famengo A. Fiameni Stefania, Boldrini Stefano, Battiston Simone, Johnson Mats, Muhammed Mamoun, and ToprakMuhammet S., (2015).Thermoelectric performance of higher manganese silicide nanocomposites, Journal of Alloys and Compounds 619, pp31-37

19. Boruah, S. and Kalita B. B.,(2018). Evaluation of physical properties of Errandi-acrylic union fabrics, Journal of Applied and Natural Science 10, no. 3, pp 925-930

20. Bharani, M., Shiyamaladevi P. S. S. and Gowda Mahendra R. V.,(2012). Characterization of seam strength and seam slippage on cotton fabric with woven structures and finish, Research journal of engineering sciences 1, no. 2; pp41-50

21. Jinlian H. U.,(2008).Fabric testing; The Textile Institute. England.

22. Winks, J.M, (1996).Properties of textiles garments. Textile Institute. Industries, 4, p253

23. Wong Y. W. H., Yuen C. W. M., Leung M. Y. S., Ku, S. K. A., and Lam H. L. I., (2006). Selected applications of nanotechnology in textiles, AUTEX Research Journal, Vol. 6, No 1, pp1-8.

24. Borah, M. P., Jose S, Kalita B.B., Shakyawar D. B. and Pandit P.(2020).Water repellent finishing on eri silk fabric using nano silica, The Journal of the Textile Institute 111, no. 5, pp701-708

25. Rupp J., Bohringer A, Yonenaga A, Hilden J.,(2001). Textiles for Protection Against Harmful Ultraviolet Radiation, International Textile Bulletin -English Edition 47, no. 6: pp8-22

26. Haerri, H. P., Haenzi, D. and Donze, J. J.(2001). Application of UV absorbers for sun protection, Melliand International 7, pp59-61

27. Holme, I. (2003). UV absorbers for protection and performance, International Dyer 4, no. 13:pp9-10

28. Bajaj, P., Kothari V. K., and Ghosh S. B.,(2000).Some innovations in UV protective clothing, Indian J. of Fibres and Textile Research 35 (4) 2, pp315 - 329

29. Bohringer B., Schindling G., Schon U., Hanke D., Hoffman K., Altmeyer R., Klotz M.L. (1997). UV Protection by Textiles, Melliand International, (3), pp165 - 167,

30. Saravanan D. (2007).UV protection textile materials, AUTEX Research Journal, March; 7(1), pp53-62,

31. Achwal, W. B. (2000). Gleanings from German literature UV protection by textiles, J. Colourage 47, no. 4: pp50-51

32. Kathiervelu, S. S. (2003). Applications of nanotechnology in fibre finishing, J. Synthetic Fibres, Vol. 32, no. 4, pp20-22,

33. Yang, C. Q., \& Wu, W. (2003).Combination of a hydroxy- functional organophosphorus oligomer and a multifunctional carboxylic acid as a flame retardant finishing system for cotton: Part II, Formation of calcium salt during laundering, Journal Fire and materials, Vol. 27(5), pp 239-251

34. Jacob, M., and Lathia, V. D. P., (1994). Blending of mulberry silk with polyester and acrylic, Indian Textile Journal 104: 48-48

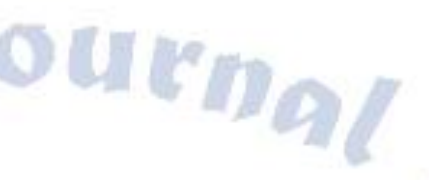

